\title{
Erratum to: Anxious Imagery in Children With and Without Autism Spectrum Disorder: An Investigation into Occurrence, Content, Features and Implications for Therapy
}

\author{
Ann Ozsivadjian ${ }^{1} \cdot$ Matthew J. Hollocks $^{2} \cdot$ Jess Southcott $^{1} \cdot$ Michael Absoud $^{1}$ • \\ Emily Holmes ${ }^{3}$
}

Published online: 8 July 2016

(C) Springer Science+Business Media New York 2016

\section{Erratum to: J Autism Dev Disord \\ DOI 10.1007/s10803-016-2840-3}

The open access funding information is missing in the acknowledgement section of the original article.

Open access for this article was funded by King's College London.

The online version of the original article can be found under doi:10.1007/s10803-016-2840-3.

Ann Ozsivadjian

Ann.ozsivadjian@gstt.nhs.uk

1 Children's Complex Neurodevelopmental Disability Service,

Children's Neurosciences Centre Newcomen at St Thomas',

South Wing, St Thomas' Hospital, Guy's and St Thomas'

NHS Foundation Trust, Westminster Bridge Road,

London SE1 7EH, UK

2 Department of Clinical Neurosciences, University of

Cambridge, Cambridge, UK

3 MRC Cognition and Brain Sciences Unit, Cambridge, UK 